\title{
Quantification of Freshness Loss and an optimization approach for managing fresh fruit exportation
}

\author{
KAMHANGWONG Damrongpol \\ Université Lumière Lyon 2 \\ Lyon, France \\ damrongpol.kam@mfu.ac.th \\ SEKHARI Aicha \\ Université Lumière Lyon 2 \\ Lyon, France \\ damrongpol.kam@mfu.ac.th
}

\author{
NEUBERT Gilles \\ EM Lyon Business School \\ Saint Etienne, France \\ gneubert@em-lyon.com \\ SUREEPHONG Pradorn \\ Chiangmai University, \\ Chiang Mai, Thailand \\ Dorn@camt.info
}

\begin{abstract}
An integrative view on logistics and product quality is one of keys to supply chain management for the fresh food industry. As it is difficult to define quality deterioration during distribution and incorporate it into logistics cost model, a quality loss assessment in term of freshness loss and a simple modelling approach to maximize net profit is proposed in this study. Export of Mangosteen from Thailand to China has been selected to be a case study and to develop the proposed model with varying environmental condition of storage and transportation, and quantity of supply and demand. The resulting model can be applied in an illustrative case study for the other fresh produce, and it can be used to plan and operate fruit exportation in term of production, distribution and inventory planning.
\end{abstract} loss;

Keywords - fresh fruit distribution; cost optimization; weight

\section{INTRODUCTION}

Controlling the product quality throughout the food supply chain is one of the most challenging tasks in today's food industry. In the supply chain of perishable fruit products, large losses are incurred between orchards and final consumers. It involved the quality insurance in the process of production, distribution, the costs for certification, auditing, and that generate responses like technological innovation to create higher efficiency and reduce costs, and there is strongly relationship with safety and sustainability in food operation management [1].

Fruit quality and assurance have meaning all aspects of food production, along with growing, harvesting, transportation, preparation and service. At all times care must be taken to ensure fruit quality is not compromised [2]. Poor food quality, whether it is caused by poor procedures or human error, is a costly and potentially deadly problem.

The interdependence between quality, safety and sustainability in fruit supply chain management is firmly. The quality and safety are depend on the initial product quality, deal with ability to supply affordable fruit with high quality and diversity, and based on changes in the fruit quality which degrades depending on environmental conditions of storage and transportation facilities during distribution [3].while they are also some of the challenges related to the responsibility of the social and environmental performance in the fruit supply chains for enhancing the transparency of food supply chains[4].

The management of fruit quality in supply chain network is sophisticated due to the perishable nature of the produce, process characteristic, high fluctuations in demand and prices, increasing consumer concerns for food safety and dependence on climate conditions. These distinctions have also affected on the limitation of the feasibility for the food quality integration in food supply chains management [5].

Many quantitative model approaches point to a certain issue which mostly concerns the characteristics of quality degradation in food products. For instance, Caixeta-Filho presented development of a LP that take into account chemical, biological and logistics constraints to the quality of the fruit to harvest, with to maximize the revenue [6], and Ferrer and et al. presented an LP model to determine a plan for the optimal scheduling of the harvest of wine grapes with the objective of minimizing operational and grape quality costs [7]. There are a few quantitative model approaches can capture all aspects in food supply chain decision such as, Aiying and et.al proposed an mixed-integer linear programming model integrated food quality which is strongly related to temperature environmental control throughout the fresh food supply chain to minimize the cost for producing during storage and transportation [8].

However, quality losses and affecting on cost of fruits are difficult to predict correctly, due to the range and dynamics of product characteristics, storage conditions and market demand. Furthermore, most quality model approaches emphasize to evaluate only quality losses to optimize total cost of production. They do not explicitly consider the effect of quality losses on decline in market value and total net profit of indeed selling in market which is necessary to apply a great deal of practice. Most company prefers to store their produce in cold 
storage to wait the price and revenue escalation, although the quality of the produce is reduced.

In order to address practical real- market, in this paper, we propose a quality assessment of fresh produce in term of weight loss evaluation coefficient and a mathematical model to optimize the net profit in which an entrepreneur had to plan how many products to export to destination market and to choose the appropriate distribution scheme.

\section{LITERATURE REVIEW}

\section{A. Fresh food distribution management}

Distribution management normally refers to the physical flows and storage of products from the final production point to the customer or end user [9]. The distribution of food is different from the distribution of other products and difficult challenge to quantify because of the continuous change in the quality from time the fresh produce leaving grower to time the reaching final consumer. Temperature and environment control is an important characteristic of many food distribution systems is essential for controlling food quality and food safety. It does, however, lead to additional energy consumption.

Most literature regarding fresh food distribution management is in field of production scheduling and mainly focused on tactical planning. Papers that comprehensively discuss distribution management of fresh produce and quality are relatively rare. Rantala presents an MIP model for designing a production-distribution model for the supply chain of a seedlings supply chain of a finish nursery company with the objective of minimizing costs)[10]. Aleotti and et al. proposed SP model for selecting the best design for the postharvest handling of fresh vegetable crops between the harvest and the final market to maximize the benefits from capital investment in food preservation facilities under conditions of uncertain production and demand [11].

\section{QUALITY DEGRADATION}

Quality of food normally refers not only to the physical properties of food products, but also to the way the product is perceived by the final consumer. This can, for instance include not only microbial aspects, but also texture or flavor. Most fresh commodities have a short shelf life and susceptibility from physiological breakdown due to natural ripening processes, water loss, temperature injury, physical damage, or invasion by microorganisms.

Freshness loss is one of the main causes of fresh fruit deterioration that reduces the marketability and profitability. It is the result of water loss from transpiration in harvested fruits. This loss of water has an immediate economic effect in that it reduces saleable weight especially, for products sold by weight. Continued water loss causes wilting and/or shriveling. Consequently, reducing water loss improves produce appearance, quality, shelf life and profitably [12].

Water loss or weight loss in fresh fruit and products during storage (or transport, for that matter) dependent on the shape and structure of the produce, the transplant factor, and the environmental conditions.
The plant factors are a constant value which are quantified by the transpiration coefficient of fruit $\left(\mathrm{K}_{\mathrm{f}}\right)$. Temperature $(\mathrm{t})$ and relative humidity $(\mathrm{h})$ are the most important environmental variables and these affect the water vapor pressure deficit, or difference, between the fruit or vegetables and its environment $\left(\mathrm{VPD}_{\mathrm{t}, \mathrm{h}}\right)$. The rate of water loss $(\mathrm{k}, \% /$ day $)$ can be described by the following general equation:

$$
\mathrm{k}_{\mathrm{t}, \mathrm{h}}=\mathrm{K} \times \mathrm{VPD}_{\mathrm{t}, \mathrm{h}}
$$

$\mathrm{VPD}_{\mathrm{t}, \mathrm{r}}$ is the driving force for water loss from the produce to the environment which can be obtained from the psychrometric chart. It is increased by increasing temperature and decreasing relative humidity.

As a general deterioration in the quality of the fruit and vegetable, temperature is an important factor in controlling product quality in supply chains. The rate of weight loss is therefore often based on the Arrhenius equation with a zero order reaction, a formula for the temperature dependence of a chemical reaction. This would lead to the following quality change for a time interval (d) and temperature (T):

$$
\Delta q_{(d, t, h)}=-k_{t, h} \bullet \exp \left[\frac{-E_{a}}{R T}\right]
$$

where $\mathrm{k}_{\mathrm{t}, \mathrm{h}}$ is a constant, $\mathrm{E}_{\mathrm{a}}$ the activation energy (an empirical parameter characterizing the exponential temperature depence), $\mathrm{R}$ the gas constant, and $\mathrm{T}$ the absolute temperature.

Weight loss has a linear relationship with time illustrated by fig. 1 . This can be lead the quality change $\Delta \mathrm{q}$ (d,t,h) for a time period, and temperature humidity to be incorporated into modelling quality in distribution.

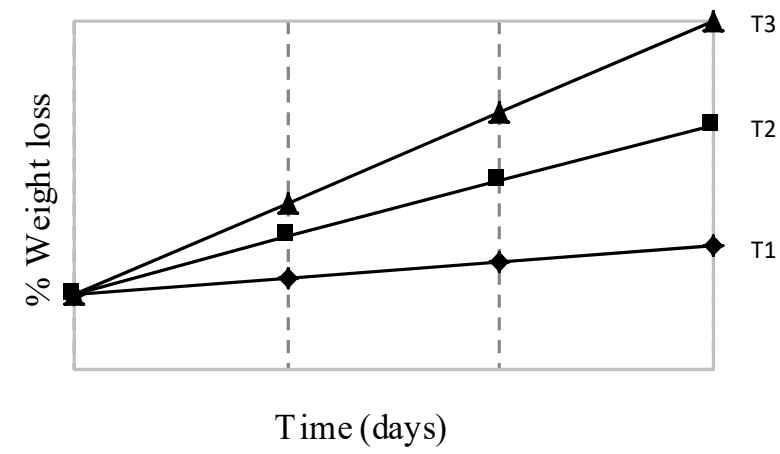

Fig 1 Illustration of fresh weight loss of fruit at various temperatures $(\mathrm{T} 1<\mathrm{T} 2<\mathrm{T} 3)$

For prediction of quality level in fruit supply chain and cost of quality loss, we can estimate the weight loss of a product at a certain location in the production and distribution network, based on an initial quality $\left(\mathrm{q}_{0}\right)$, and subsequent storage periods with time interval and weight loss rate. 


\section{MODELLIING IN FRUIT EXPORTATION}

In this section, we presents quantification of weight loss in fruit exportation, and the model approach which take into account the cost of quality loss due to the loss of weight in each transportation route.

\section{A. Representing fruit quality degradation during distribution}

To study the effect of environmental conditions on weight loss and cost, mangosteen (G. mangostana L.) obtained from a commercial orchard in Chanthaburi Province, Eastern Thailand. Fruits were selected for color (light greenish yellow with 51-100\% scattered pink spots) and size $(75-90 \mathrm{~g})$ uniformity, and then transported by refrigerated truck $(13 \circ \mathrm{C})$ to the laboratory within $6 \mathrm{hrs}$. The fruits were kept at $13{ }^{\circ} \mathrm{C}$, $20^{\circ} \mathrm{C}$, and $30^{\circ} \mathrm{C}(75 \% \mathrm{RH})$. The weight of mangosteen was monitored at various storage times: $0,5,10,15,20$ and 25 days. The rate of water loss from fruit at various storage temperatures and transpiration coefficient of fruit were determined by equation 1

To study the environmental conditions in transit, three temperature and humidity data loggers were put to the fruit packaging system ( non-returnable polypropylene box with internal dimension $(33 \times 44.5 \times 16 \mathrm{~cm})$ supported in both bottom and top with sponge (polyurethane), as a cushion system) and loaded into 40 foots shipping containers at about 21,460 $\mathrm{kg} /$ container. The fruits were shipped at $13{ }^{\circ} \mathrm{C}$ and the distance in range $1,674-5,944 \mathrm{~km}$. Temperature and $\% \mathrm{RH}$ data were recorded in real time for $3 \mathrm{~s}$ for every $10 \mathrm{~min}$ of road travel. The case study concerns transportation from the collecting center in Chantaburee (CB), Thailand to three main fruit distribution center of China: Kunming (KM), Nanning (NN) and Guangzhou (GZ), China, by nine exporting routes (i), as shown the detail in table1. On arrival to the Chinese distribution center, the data were transferred to a to calculate the average temperature, relative humidity computer and VPD t,r.

The relative \%weight loss and cost of each transportation route were estimated in term of the weight loss evaluation coefficient $\left(\varpi_{i}\right)$, as show in equation 3 . This coefficient was used to adjust the cost per ton for each transportation route that will be paid to the exporter. If the original cost at the exporter is PDi ,the raw material cost at collector, after taking into account the loss of product will be $P D i^{*} \varpi \mathrm{i}$. The objective is to integrate the weight loss evaluation coefficient as a parameter in the cost to exporting model to evaluate the net profit for fruit exportation.

$$
\omega_{i}=\left[\frac{1}{1-\left[\frac{\% \text { weight loss }}{100}\right]}\right]
$$

A completely randomized design was used with all treatments. Temperature , \% RH data and \%weight loss each transportation route were subjected to analysis of variance (ANOVA) and mean comparisons were carried out by
Duncan's multiple range testing and the correlation coefficient between the time and the \%weight loss were analyzed by Pearson's correlation. Analysis was performed using the SPSS package (SPSS 11.0 for windows, SPSS Inc., Chicago, IL, USA). The statistical significance was considered to be $\mathrm{p}<0.05$.

TABLE I. THE DETAILS OF THE FRUIT SHIPMENTS STUDIED.

\begin{tabular}{|c|c|c|c|}
\hline No & Exporting Routes & $\begin{array}{l}\text { Distance } \\
(\mathbf{k m})\end{array}$ & Vehicle \\
\hline 1 & R3A Road: CB - CR - MH -KM & 1,863 & \multirow{2}{*}{$\begin{array}{l}\text { Refrigerator truck (RT), } \\
\text { 24-wheel, 55,000 kg of } \\
\text { capacity. }\end{array}$} \\
\hline 2 & R3B Road: CB - CR - MG -KM & 1,817 & \\
\hline 3 & $\begin{array}{l}\text { Road and River shipment: } \\
\text { [1] CB - CR change [2] LR - JH - } \\
\text { KM }\end{array}$ & 1,768 & $\begin{array}{l}\text { [1] RT, 24-wheel, 55,000 } \\
\mathrm{kg} \text { of capacity. } \\
\text { [2] Unrefrigerated cargo } \\
\text { ship, 150TEU of capacity. }\end{array}$ \\
\hline 4 & R12 Road: CB- NP- VA- GZ & 2,669 & \multirow{2}{*}{$\begin{array}{l}\text { RT, 24-wheel, } 55,000 \mathrm{~kg} \\
\text { of capacity. }\end{array}$} \\
\hline 5 & R9 Road: CB- MH - VA - GZ & 2,751 & \\
\hline 6 & $\begin{array}{l}\text { Road and Ocean shipment: } \\
\text { [1] CB-MH change [2] VA- NN }\end{array}$ & 1,674 & \multirow{4}{*}{$\begin{array}{l}\text { [1] RT, 24-wheel, 55,000 } \\
\text { kg of capacity. } \\
\text { [2] Refrigerator cargo } \\
\text { ship, 520-foot dry cargo } \\
\text { ship }\end{array}$} \\
\hline 7 & $\begin{array}{l}\text { Ocean shipment: } \\
\text { [1] CB-LB change [2] HK - GZ-NN }\end{array}$ & 4,367 & \\
\hline 8 & $\begin{array}{l}\text { Ocean shipment: } \\
\text { [1] CB-LB change [2] SS- GZ-NN }\end{array}$ & 5,944 & \\
\hline 9 & $\begin{array}{l}\text { Ocean shipment: } \\
\text { [1] CB-LB change [2] SS- NN }\end{array}$ & 4,825 & \\
\hline
\end{tabular}

Note. CR : Chiang Rai, MH: Mukdahan, MG: Muangla, LR : Lan Chang River, JH: Jing Hong, NP: Nakhon Phanom, VA: Vung Ang, LB: Laemchabang, HK: Hong Kong, SP: Singapore

\section{B. Case study analysis}

Studying the effect of temperature and \%RH percentage of weight loss for each transportation route is presented in fig 3 . The results revealed that the RWL occurred in the mangosteen stored in the $30{ }^{\circ} \mathrm{C}$ was the highest at $3.1274 \%$ ws/day, while the fruits in $25{ }^{\circ} \mathrm{C}, 20{ }^{\circ} \mathrm{C}$ and $13^{\circ} \mathrm{C}$ were lower at 2.1058 $\%$ ws/day, $1.7890 \% \mathrm{ws} /$ day, and $1.1916 \% \mathrm{ws} /$ day, respectively. $(\mathrm{p}<0.05)$. The $\% \mathrm{WL}$ of fruits in all treatments were directly proportional to the time to delivery of fruit. They are considered as a linear function which can be confirmed by the positive correlation coefficient value of 0.9673 at $13^{\circ} \mathrm{C}, 0.9892$ at $20^{\circ} \mathrm{C}, 0.9861$ at $25^{\circ} \mathrm{C}$ and 0.9872 at $30^{\circ} \mathrm{C}$, respectively.

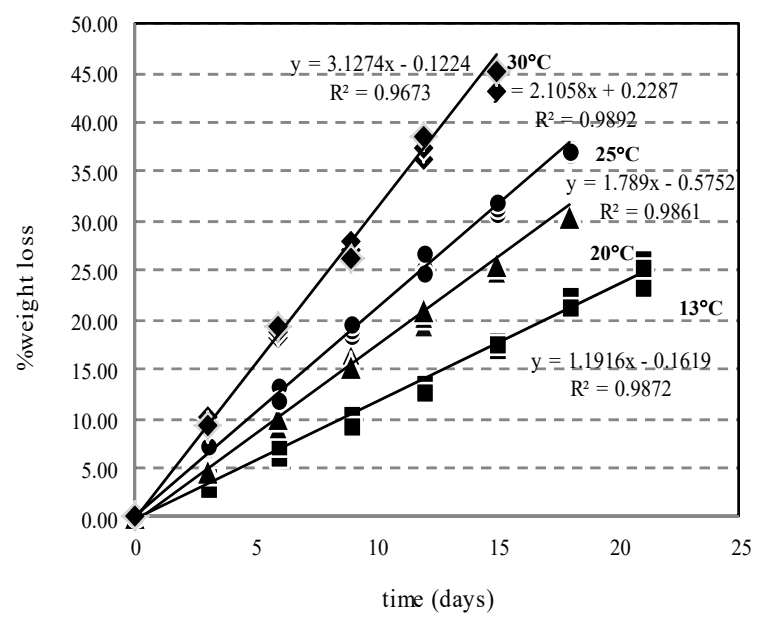

Fig. 3 Weight loss (\%) in mangosteen stored at $13^{\circ} \mathrm{C} / 75 \% \mathrm{RH}$ (घ), $20^{\circ} \mathrm{C} / 75 \% \mathrm{RH}(\boldsymbol{\Delta}), 25^{\circ} \mathrm{C} / 85 \% \mathrm{RH}(\bullet)$, and $30^{\circ} \mathrm{C} / 85 \% \mathrm{RH}$ $(\diamond)$ at various day. 
Weight loss or water loss in mangosteen is the factor that contributes most to for products sold by weight this will have economic consequences. More severe water loss results in a reduction in appearance quality including wilting, shriveling, less gloss, and limpness, which will reduce market value of fruit, as show in figure 4.
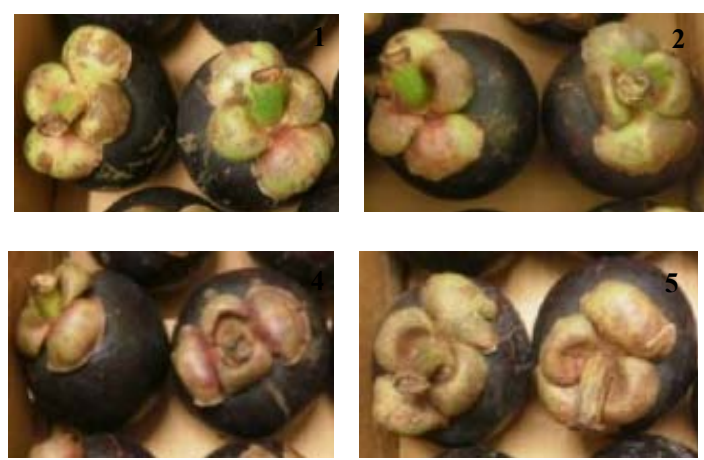

Fig.4 A visual appearance of mangosteens stored at $13^{\circ} \mathrm{C} / 75 \%$ RH where $1=0-2 \% \mathrm{WL} ; 2=9-10 \% \mathrm{WL} ; 3=19$ $20 \% \mathrm{WL}$; and $4=29-30 \% \mathrm{WL}$;

To determine TC of mangosteen by equation 1, VDP obtained using the psychrometric chart which gives a RH and water vapor pressure, and RWL from each treatment were graphic representation of the relationship between temperature, be substituted in the equation 1. The results for TC of mangosteen are shown in Table II where vapor pressure of produce is assumed to be at $100 \% \mathrm{RH}$. The average of TC for mangosteen is $0.28 \mathrm{mg} /(\mathrm{kg}$.sec.MPa) which will be applied to study the relative \%weight loss and the weight loss evaluation coefficient in each route of exportation.

TABLE II. THE TRANSPIRATION COEFFICIENT AND RATE OF WEIGHT LOSS OF MANGOSTEEN STORED AT $13^{\circ} \mathrm{C} / 75 \% \mathrm{RH}, 20^{\circ} \mathrm{C} / 75 \% \mathrm{RH}, 25^{\circ} \mathrm{C} / 75 \% \mathrm{RH}$ AND $30^{\circ} \mathrm{C} / 75 \% \mathrm{RH}$

\begin{tabular}{|c|c|c|c|c|c|}
\hline \multirow{2}{*}{$\begin{array}{c}\mathrm{T} \\
\left({ }^{\circ} \mathrm{C}\right)\end{array}$} & \multicolumn{2}{|c|}{ Vapor pressure (mbar) } & \multirow[t]{2}{*}{ VDP } & \multirow{2}{*}{$\begin{array}{c}\text { RWL } \\
\text { (\%WL/day) }\end{array}$} & \multirow{2}{*}{$\begin{array}{c}\text { TC } \\
\text { (mg/(kg.sec. } \\
\text { MPa) }\end{array}$} \\
\hline & $\begin{array}{l}100 \% \text { RH } \\
\text { (produce) }\end{array}$ & $\begin{array}{c}75 \% \text { RH } \\
\text { (Air) }\end{array}$ & & & \\
\hline 13 & 14.97 & 11.23 & 3.74 & $1.11 \mathrm{~d}$ & 0.30 \\
\hline 20 & 23.39 & 17.54 & 5.85 & $1.62 \mathrm{c}$ & 0.28 \\
\hline 25 & 31.69 & 23.76 & 7.93 & $2.05 b$ & 0.26 \\
\hline 30 & 42.46 & 31.84 & 10.62 & $3.02 \mathrm{a}$ & 0.28 \\
\hline \multicolumn{5}{|c|}{ Average of TC } & 0.28 \\
\hline
\end{tabular}

*For RWL, a, b different letters within a column indicate significantly different $(\mathrm{P}<0.05, \mathrm{~N}=27)$.

Studying the environmental transportation conditions and the percentage of weight loss for each transportation route is presented in table 2 . The route 3 is not operate temperature in part of cargo ship from LR to $\mathrm{JH}$, which would result in the maximum VDP (3.44) and the rate of weight loss $(1.38$ $\% \mathrm{WL} /$ day) while the other routes is lower because they have control temperature throughout transportation route. However, considering the $\% \mathrm{WL}$ and the WLC, we found that the route 8 and 9 had the highest \%WL (16.71\%) because they spent the longest time to delivery (15 days) while the other routes are lower.
TABLE III. THE DETAILS OF THE FRUIT SHIPMENTS STUDIED TRANSPIRATION COEFFICIENT OF MANGOSTEEN.

\begin{tabular}{|c|c|c|c|c|c|c|c|}
\hline \multirow[t]{2}{*}{ Route } & \multirow{2}{*}{$\begin{array}{c}\text { Time to } \\
\text { delivery (day) }\end{array}$} & \multicolumn{3}{|c|}{ Environmental condition } & \multirow{2}{*}{$\begin{array}{c}\text { RW } \\
\mathbf{L}\end{array}$} & \multirow{2}{*}{$\begin{array}{c}\% W \\
\text { L }\end{array}$} & \multirow{2}{*}{$\begin{array}{c}\text { WLC } \\
\left(\varpi_{i}\right)\end{array}$} \\
\hline & & $\left({ }^{\circ} \mathrm{C}\right)$ & \%RH & VDP & & & \\
\hline 1 & 3 & $15.7 \mathrm{~b}$ & $73.2 \mathrm{~d}$ & 2.72 & $1.33 \mathrm{a}$ & $4.00 \mathrm{~d}$ & $0.9600 \mathrm{a}$ \\
\hline 2 & 3 & $15.7 \mathrm{~b}$ & $73.2 \mathrm{~d}$ & 2.72 & $1.33 \mathrm{a}$ & $4.00 \mathrm{~d}$ & $0.9600 \mathrm{a}$ \\
\hline 3 & 5 & $20.2 \mathrm{a}$ & $79.1 \mathrm{a}$ & 3.44 & $1.38 \mathrm{a}$ & $6.91 \mathrm{c}$ & $0.9309 \mathrm{a}$ \\
\hline 4 & 5 & $15.0 \mathrm{~b}$ & $74.1 \mathrm{c}$ & 2.72 & $1.23 \mathrm{~b}$ & $6.16 \mathrm{c}$ & $0.9384 \mathrm{a}$ \\
\hline 5 & 5 & $15.0 \mathrm{~b}$ & $74.1 \mathrm{c}$ & 2.72 & $1.23 \mathrm{~b}$ & $6.16 \mathrm{c}$ & $0.9384 \mathrm{a}$ \\
\hline 6 & 10 & $14.5 \mathrm{c}$ & $75.3 b$ & 3.41 & $1.14 \mathrm{c}$ & $11.39 \mathrm{~b}$ & $0.8861 \mathrm{~b}$ \\
\hline 7 & 10 & $14.5 \mathrm{c}$ & $75.3 \mathrm{~b}$ & 3.41 & $1.14 \mathrm{c}$ & $11.39 \mathrm{~b}$ & $0.8861 \mathrm{~b}$ \\
\hline 8 & 15 & $14.3 \mathrm{c}$ & $75.5 \mathrm{~b}$ & 3.20 & $1.11 \mathrm{c}$ & 16.71a & $0.8329 \mathrm{~b}$ \\
\hline 9 & 15 & $14.3 \mathrm{c}$ & $75.5 \mathrm{~b}$ & 3.20 & $1.11 \mathrm{c}$ & $16.71 \mathrm{a}$ & $0.8329 \mathrm{~b}$ \\
\hline
\end{tabular}

The environmental condition of transportation and time to delivery in each route have an impact on the logistics costs which it is represented in term of WLC and incorporated as a part of model. For this experiment, we found that the route 6,7 , 8 and 9 have the most effect on the cost of logistics at range $0.8329-0.8861$ of WLC, while the route $1,2,3,4$ and 5 are less at range $0.9384-0.9600$ of WLC $(p<0.05)$.

\section{MODEL FORMULATION}

Our modelling is based on case study mangosteen exportation from Thailand to China shown in figure 2. The fruit products are distributed direct from collecting center to three main distributions by nine routes. The objective of model is to optimize the net profit of exporter by considering the difference between total cost of production and the revenue of fruit. The total cost of production comprises the common logistics cost and the cost of weight loss during distribution, while the revenue depends on the sell price which is associated with the quantity of fruit on market and fruits demanded by consumers at various time. After the fruits are delivered to distribution center, exporter can choose to store in room cooling and/or to sell immediately if the sell price of fruit at that time is low and high, respectively.

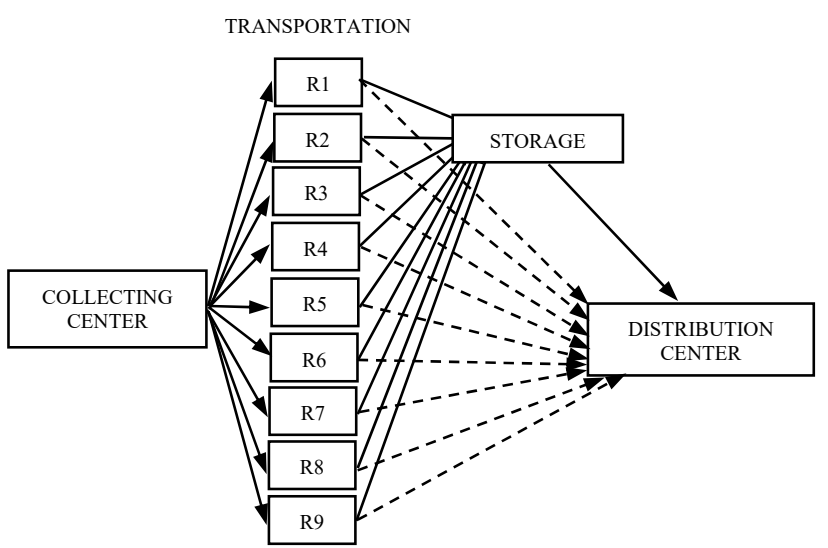

Fig.2 Network represent of fruit supply chain structure

The weight loss level degree is varying depending on conditions of transportation and storage each routes. As mention above, to plan and choose the appropriate distribution scheme under the various constraints, the model requires introducing the following decision variables and parameters into the model: 


\section{Decision variables:}

$\mathrm{x}_{\mathrm{i}}$ the quantity of fruit (in ton) exported in day (i)

$\mathrm{y}_{\mathrm{i}} \quad$ the quantity of fruit (in ton) exported in day (i) and immediately sold in arrived day $(i+d)$

$\mathrm{Z}_{\mathrm{i}, \mathrm{k}}$ the quantity of fruit (in ton) exported in day (i) and sold after storage for $(k)$ day

$\mathrm{S}_{\mathrm{i}} \quad$ the quantity of fruit sold immediately in day (i) by without storage

$\mathrm{W}_{\mathrm{i}}$ the quantity of fruit from inventory sold in day (i) after storage

Parameters :

$m_{i} \quad$ production cost of fruit

$f_{i} \quad$ transportation costs for transportation in route $j$

$g_{k} \quad$ cooling costs for storage k day.

$P S_{i} \quad$ sell price of fruit in day $i$

$\varpi_{I, j}{ }^{k} \quad$ WLC of transportation in route $j$ and storage $\mathrm{k}$ day

$S_{i, j} \quad$ quantity of fruit supply from orchard in day $i$.

The LP model considering revenue, common logistics cost and freshness losses in term of WLC were formulated to optimize the scheduling fresh fruit exporting operations under maximize the net profit (NP) for fruit exporter which can be shown as the follow;

$\operatorname{Max} \mathrm{NP}=\sum_{i=1}^{n} r_{i}-\left[\begin{array}{l}\sum_{i=1}^{n=1} \sum_{j=1}^{m=1} m_{i} x_{i j}+\sum_{i=1}^{n=1} \sum_{j=1}^{m=1} f_{j} x_{i j}+ \\ \sum_{i=1}^{n=1} \sum_{j=1}^{m=1} \sum_{k=1}^{0=1} g_{k} z_{i, j}^{k}\end{array}\right]$

Subject to:

$r_{i, j}^{k}=\left[S_{i, j}+w_{i, j}^{k}\right] * P S_{i} *\left[1-\varpi_{i, j}^{k}\right]$

$x_{i, j}^{k}=y_{i, j}^{k}+\sum_{k=1}^{m} z_{i, k}$

$S_{i, j}= \begin{cases}0 & : i<d+1 \\ y_{i-2} & : i \geq d+1\end{cases}$

$w_{i, j}^{k}= \begin{cases}0 & : i<d+r \\ \sum_{k=1}^{m} z_{(i-d-k-1), k} & : i \geq d+r\end{cases}$

$x_{i}=S R_{i}$

$y_{i} \geq 0$

$Z_{i k} \geq 0$

To maximize NP of mangosteen export, the model was developed by using the optimization of the difference between the revenue and the cost of exportation. The revenue depends on freshness and sell price of fruit at various time while the cost of exportation consist of production costs, transportation cost and cooling costs for storage which depend on raw material cost in each day, transportation routes and storage time.

In constraint (5), the revenue model is comprised of the revenue of fruit that was sold immediately at arrive time $\left(s_{i, j}\right)$ by without storage, the revenue of fruit from inventory $i$ after storage at various time and $\left(w_{i, j}{ }^{k}\right)$ and TWC $\left(1-\varpi_{i, j}{ }^{k}\right)$ of transportation in route $\mathrm{j}$. In (6), the total quantity of exported fruit in day $i$ cannot be greater than the combination of quantity of fruit sold immediately by without storage in day $i$ and quantity of fruit in inventory sold in day i after stored in room cooling for $k$ day. Constraint (8) ensures the exported fruit will be not sold before they arrive to distribution center. Constraint (9) ensures the fruit in inventory will be not sold before storage date. Constraint (10) ensures that total amount of mangosteen exported at day $i$ cannot be greater than the maximum mangosteen supply from orchard (St) in each day. For this model, we assume that there is ultimate capacity of room cooling at distribution center.

\section{CONCLUSION}

The environmental transportation condition and time to delivery have an impact on the weight loss, logistics costs and the efficiency of the distribution process of fruit. These parameters are proposed as a part of a cost model in term of weight loss evaluation coefficient to optimize profit for fruit exporter.

The model approach is presented linear programming model for the planning of food production and distribution with a focus on not only common logistics cost but also weight loss of produce, which is strongly related to temperature and humidity control throughout the supply chain. The approach can help the logistics exporter to plan and operate fruit exportation in term of production, distribution and inventory planning and it can be also applied to the other fresh produce. However, this paper considered only a single product and quality loss in the distribution network. Future work could therefore include the regard of multiple products and the other quality loss such as physical injury due to transportation. This will have to study quality loss models for each of these products and interactions between the different products.

\section{ACKNOWLEDGMENT}

The author would like to thank Université Lumière Lyon 2 Lyon, France and the Erasmus Mundus Programme for financial support. We are thankful to Dr. NEUBERT Gilles, Dr. SEKHARI Aicha and Dr. SUREEPHONG Pradorn.

\section{REFERENCES}

[1] Renzo A. Poorya F. ·and Martin G.. Quality, safety and sustainability in food distribution: a review of quantitative operations management approaches and challenges. OR Spectrum. 2010. 32:863-904 
[2] L. Manning R.N. Baines S.A. Chadd, ,"Quality assurance models in the food supply chain", British Food Journal, Vol. 108 Iss 2. 2006. pp. 91 104

[3] Fritz M, Schiefer G. Food chain management for sustainable food system development: A European research agenda. Agribusiness. 2008. 24(4):440-452

[4] Smith BG. Developing sustainable food supply chains. Philos Trans R Soc. 2008. B 363(1492):849-861

[5] Yared Lemma, Daniel Kitaw, Gulelat Gatew. Loss in Perishable Food Supply Chain: An Optimization Approach Literature Review. International Journal of Scientific \& Engineering Research. 2014, Volume 5, Issue 5.

[6] Caixeta-Filho, J.V., Orange harvesting scheduling management: A case study. Journal of the Operational Research Society. 2006. 57 (6), 637-642.

[7] Ferrer, J.C., MacCawley, A., Maturana, S., Toloza, S., Vera, J., 2008. An optimization approach for scheduling wine grape harvest operations.
International Journal of Production Economics 112 (2), 985-999.

[8] Aiying R., Renzo A. and Martin G., An optimization approach for managing fresh food quality throughout the supply chain Int. J. Production Economics, 2011. V.131, p. 421-429

[9] Rushton A, Croucher P, Baker P (2006) The Handbook of Logistics and DistributionManagement, 3rd edn. Kogan Page, London, UK

[10] Rantala, J.,. Optimizing the supply chain strategy of a multi-unit finish nursery. Silva Fennica. 2004. 38 (2), 203-215.

[11] Aleotti, L.O., Araujo, R., Yahya, R., 1997. Selection of postharvest technology routes by mixed-integer linear programming. International Journal of Production Economics 49, 85-90.

[12] D. Holcroft. Water Relations in Harvested Fresh Produce. PEF White Paper No. 15-01. The Postharvest Education Foundation (PEF). 2015. May 